\title{
Conversando sobre Política na Situação Psicoterapêutica
}

\author{
Talking about Politics in \\ the Psychotherapeutic Context \\ Conversando sobre Política en \\ la Situación Psicoterapéutica
}

Roque Tadeu Gui

Universidade de

Brasília

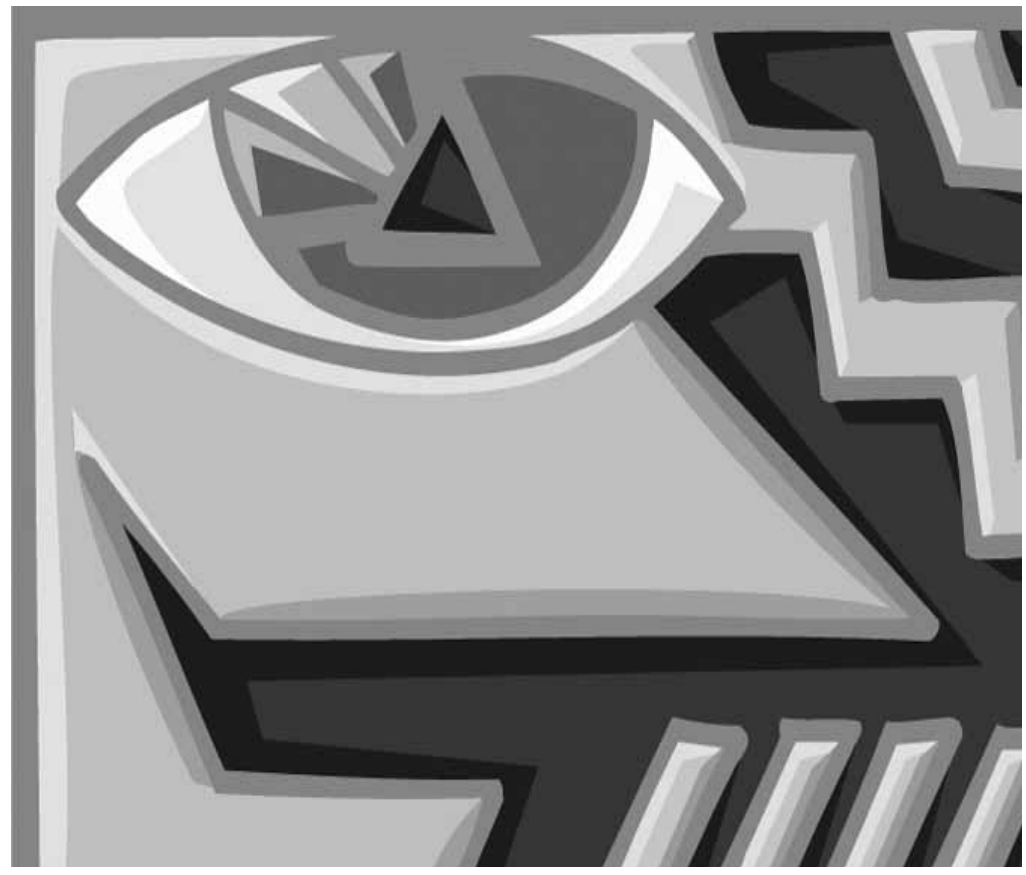


Nenhuma sociedade

que esquece a arte de questionar ou

deixa que essa arte caia em desuso

pode esperar

encontrar respostas

para os problemas

que a afligem certamente não

antes que seja tarde

demais e quando

as respostas, ainda

que corretas, já se tornaram irrelevantes.

(Bauman, 2000, p. 14)

Resumo: Neste trabalho, é analisada a intervenção clínica sobre o material político apresentado na situação terapêutica, buscando-se compreender as relações existentes entre desenvolvimento psicológico e desenvolvimento político da personalidade. Utilizou-se a metodologia qualitativa: 24 terapeutas de São Paulo e Brasília, de ambos os sexos e diferentes orientações clínicas, responderam a um questionário, e 7 deles participaram de grupo focal sobre o tema clínica e política. Os terapeutas lidam com material político de maneira preferencialmente simbólica/interpretativa, muitas vezes associada a certa maneira "realista" de considerar o tema. O desenvolvimento político da pessoa é percebido como decorrente do desenvolvimento psicológico ou, então, favorecido por este, mas não ocorrendo necessariamente. Engajamentos políticos são vistos freqüentemente como sintomas de mau-funcionamento psíquico, e os terapeutas não identificam as vivências sociopolíticas como estímulos ao desenvolvimento psíquico. Confirma-se a existência de uma cisão entre a face pública da profissão, que se apresenta apolítica, e a face privada, representada por profissionais que vivem engajamentos sociopolíticos. Sugere-se o aprofundamento dos estudos sobre as relações entre o desenvolvimento psicológico e o desenvolvimento político da personalidade para subsidiar as abordagens psicoterapêuticas no manejo de material político.

Palavras-chave: Psicologia política. Desenvolvimento da personalidade. Psicoterapia analítica. Setting.

Abstract: This study analyses the clinical intervention about the political material that emerges in the terapeutic context and has the aim of comprehending the relations between the psychological development and the personality political development. The qualitative methodology was adopted: 24 therapists from São Paulo and Brasília, male and female and from different clinical orientations, answered a survey, and 7 of them participated in a focal group about the subject clinical practice and politics. The way of dealing with political issues is preferably simbolic-interpretative, although many times associated with a "realistic form" of considering the subject. The personal political developement is perceived by terapists as coming from psychological developement, or facilitaded by it, but not occurring necessarily. Many times the therapists understand the political involvement as a symptom of the psychic malfunctioning and don't identify sociopolitical experiences as a stimulus to the development of the psyche. The study confirms that there is a split between the public face of the profession, that appears in an apolitic way, and the private face, represented by professionals who have political experience and participation in sociopolitical processes. Greater deepening in the studies about the relations between the psychological development and the political development that may inform the different approaches in dealing with political topics in therapeutic situation is suggested.

Keywords: Political psychology. Development of personality. Analytical psychoterapy. Setting.

Resumen: En este trabajo, es analizada la intervención clínica sobre el material político presentado en la situación terapéutica, buscándose comprender las relaciones existentes entre desarrollo psicológico y desarrollo político de la personalidad. Se utilizó la metodología cualitativa: 24 terapeutas de Sao Paulo y Brasilia, de ambos los sexos y diferentes orientaciones clínicas, contestaron a un cuestionario, y 7 de ellos participaron en grupo con enfoque sobre el tema clínica y política. Los terapeutas manejan material político de manera preferentemente simbólica/interpretativa, muchas veces asociada la cierta manera "realista" de considerar el tema. El desarrollo político de la persona es percibido cómo consecuente del desarrollo psicológico o, entonces, favorecido por éste, pero no ocurriendo necesariamente. Compromisos políticos son vistos frecuentemente como síntomas de mal-funcionamiento psíquico, y los terapeutas no identifican las vivencias sociopolíticas como estímulos al desarrollo psíquico. Se confirma la existencia de una cisión entre el lado público de la profesión, que se presenta apolítico, y el lado privado, representado por profesionales que viven compromisos sociopolíticos. Se sugiere el ahondamiento de los estudios sobre las relaciones entre el desarrollo psicológico y el desarrollo político de la personalidad para subvencionar los abordajes psicoterapêuticas en el manejo de material político.

Palabras clave: Psicología política. Desarrollo de la personalidad. Psicoterapia analítica. Setting.

Como se situa a clínica psicológica diante da subjetividade sofredora do homem-mundo contemporâneo? Quais são as conexões existentes entre o político, entendido como aquilo que diz respeito à vida da e na pólis, e o pessoal, dimensões que se imbricam, conscientemente ou não, nas queixas de nossos pacientes? Como os profissionais da psicoterapia - na diversidade e singularidade de suas abordagens - lidam com essa interface?

Os psicoterapeutas vivenciam o caráter sigiloso do seu fazer clínico, considerado 


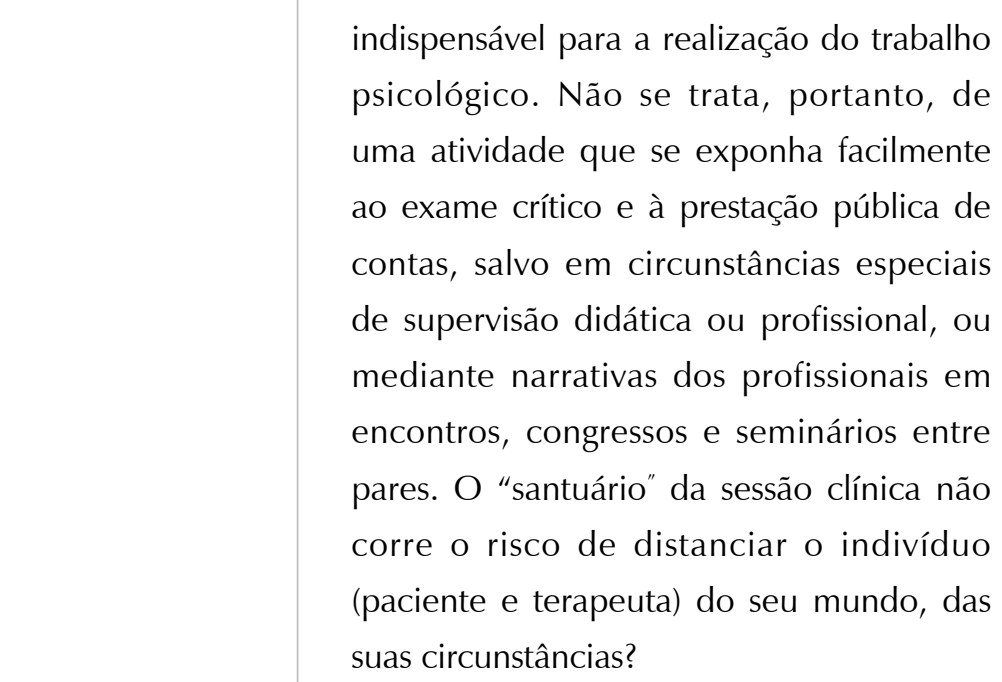

Mais inquietante será, contudo, uma resposta que aponte 0 terapeuta como possivel agente apartador do indivíduopaciente em relação ao seu mundo, em decorrência de sua ideologia terapêutica e de suas convicções políticas

(Bock, 1999).
Talvez argumentemos que todas as vivências de nosso paciente são bem-vindas ao encontro terapêutico e que, portanto, a dimensão política do self aí também encontra lugar. Mais inquietante será, contudo, uma resposta que aponte o terapeuta como possível agente apartador do indivíduopaciente em relação ao seu mundo, em decorrência de sua ideologia terapêutica e de suas convicções políticas (Bock, 1999).

Este trabalho, que constitui a parte empírica de um estudo teórico mais amplo (Gui, 2005), pretende contribuir para o debate científico sobre a prática da psicoterapia, oferecendo reflexões sobre o fenômeno clínica-política. Propõe-se, então, analisar a relação entre desenvolvimento psicológico e desenvolvimento político da pessoa, a partir das contribuições da Psicologia analítica de Carl Gustav Jung (1875-1961) e da experiência de psicoterapeutas de diferentes orientações teórico-clínicas. Conclui-se que precisamos estar atentos não apenas às patologias individuais mas também às "patologias" do mundo que incidem sobre, e conformam, os indivíduos (Hillman, 1993).

\section{Fundamentação teórica}

O estudo articula a Psicologia clínica com idéias da Psicologia social, da Psicologia política, da Sociologia e da Filosofia, em busca de maior compreensão das relações entre desenvolvimento psicológico e desenvolvimento político da personalidade. Questiona, ainda, as implicações dessas relações para a prática psicoterapêutica/ analítica.

\section{Conceito de política}

O termo política é entendido pelo senso comum em referência às questões relativas à participação do cidadão em organizações político-partidárias, ao exercício de cargos na estrutura formal das instâncias políticas do País ou, mais simplesmente, ao exercício do voto. Neste estudo, inspiro-me, explicitamente, nas concepções de Arendt (2002):

\begin{abstract}
Se alguém quiser ver e conhecer o mundo tal como ele é "realmente", só poderá fazê-lo se entender o mundo como algo comum a muitos, que está entre eles, separando-os e unindo-os, que se mostra para cada um de maneira diferente e, por conseguinte, só se torna compreensível na medida em que muitos falarem sobre ele e trocarem suas opiniões, suas perspectivas uns com os outros e uns contra os outros. Só na liberdade do falar um com o outro nasce o mundo sobre o qual se fala, em sua objetividade visível de todos os lados. (p. 60)
\end{abstract}

Se desejarmos ver e conhecer o mundo tal como ele é vivenciado por nosso paciente/ cliente, precisaremos entender que esse mundo é um mundo compartilhado com outros, mundo esse que separa, ao mesmo tempo em que une, as pessoas. É necessário, 
pois, falar sobre ele, ouvir opiniões e perspectivas e, sobretudo, lembrar, que o viver em um mundo real e o falar sobre ele com outros convergem para a construção da realidade do mundo, e isso vale tanto para pacientes quanto para terapeutas/analistas.

O conceito de "política" é utilizado, então, em um sentido amplo, que nos remete a todos os temas relacionados com a vida da e na pólis. Além do referencial conceitual oferecido por Arendt, lança-se mão, ainda, do campo conceitual proposto por Samuels (1995) em trabalho similar ao deste estudo:

Por "política", entendo os arranjos e conflitos combinados no interior de uma instituição, ou numa só sociedade, ou entre os países do mundo para a organização e distribuição de recursos e poder, especialmente poder econômico. A política diz respeito ao modo pelo qual o poder é mantido ou desdobrado pelo Estado, por instituições e por interesses setoriais para manter a sobrevivência, determinar comportamentos, obter controle sobre os outros e, mais positivamente talvez, realçar a qualidade da vida humana. A política implica esforços para mudar ou transformar esses arranjos e esforços para mantê-los. ... Num nível mais pessoal, há um segundo tipo de política. Aqui, o poder político reflete conflitos sobre a intervenção, significando a capacidade de escolher livremente agir e que ação tomar em uma dada situação. Essa é uma política no nível dos sentimentos. (pp. 21-22)

\section{Metodologia}

O estudo é descritivo e exploratório. Embora inspirado no estudo de A. Samuels, adaptações foram feitas no que diz respeito aos participantes e à metodologia utilizada. Procurou-se, contudo, fazer comparações contextualizadas entre os dois estudos (Vasconcelos, 2002).
No que se refere à relação entre o tempo de realização da pesquisa e o tempo de ocorrência do fenômeno (Vasconcelos, 2002), a pesquisa foi do tipo ex post, ou seja, o foco principal referiu-se a fenômenos ocorridos no passado (experiência dos participantes da pesquisa com o manejo de material político na situação terapêutica e as relações estabelecidas pelos terapeutas entre desenvolvimento pessoal e desenvolvimento político da pessoa). Quanto ao tipo de corte no tempo (Vasconcelos, 2002), o estudo se caracterizou pelo corte longitudinal, uma vez que se pretendeu conhecer a experiência dos terapeutas com material político emergente na situação terapêutica, ao longo de sua vida profissional e a partir do seu relato feito no presente.

Instrumentos de pesquisa

A pesquisa foi conduzida com a utilização de dois instrumentos:

a) Questionário - adaptou-se questionário utilizado por Samuels (1995), buscandose levantar informações para responder às perguntas de pesquisa e identificar questões que possibilitassem uma exploração qualitativa mais aprofundada por meio de grupo focal.

b) Grupo focal - estratégia de investigação de processos e representações sociais e culturais de grupos sociais específicos, referentes a temas, valores, atitudes e hábitos e formação de opiniões (Gui, 2003; Vasconcelos, 2002). Tendo em vista a limitação de recursos disponíveis, realizou-se um único encontro de grupo focal, não se cumprindo o quesito metodológico que recomenda a realização de 
tantos encontros quantos forem necessários para se atingir o ponto de saturação informacional (Gui, 2003). Contudo, para os propósitos do presente estudo, quais sejam, o de gerar questões exploratórias que possam suscitar novas pesquisas, considerou-se a estratégia satisfatória. Procurou-se equilibrar a composição do grupo no que diz respeito ao sexo e à orientação terapêutica dos participantes.

\section{Participantes}

\section{Responderam ao questionário 24} psicoterapeutas (18 mulheres e 6 homens), 10 oriundos de São Paulo e 14 de Brasília, na faixa etária de 30 a 60 anos, com 8 a 30 anos de profissão, praticantes de sete orientações clínicas diferentes: Psicologia analítica, psicanálise, psicodrama, terapia guestáltica, terapia reichiana, psicoterapia breve e "orientação múltipla" (sic), todos com experiência em consultório particular, 4 com experiência em instituição pública e 1 em instituição privada; 19 deles eram filiados a associações profissionais.

A quantidade de terapeutas junguianos, superior à das demais orientações, deveuse à oportunidade de contactá-los por agenciamento de amigos analistas da cidade de São Paulo. Embora não fosse esperado um número tão expressivo $(45,4 \%$ dos participantes), resolveu-se não descartar nenhum dos questionários respondidos. Para o grupo focal, foram convidados quatro psicoterapeutas mulheres e três psicoterapeutas homens, todos de Brasília, na faixa etária de 41 a 60 anos, com 8 a 20 anos de profissão, de seis orientações clínicas diferentes. Todos têm prática em consultório particular, dois deles também com experiência em instituição pública e outro com experiência em instituição privada, e quatro deles com filiação a associações profissionais. Os participantes do grupo focal responderam previamente ao questionário e suas respostas também foram consideradas no tratamento das informações originadas por meio desse instrumento.

As informações colhidas durante o encontro de grupo focal foram gravadas em fitascassete, posteriormente degravadas e seu material impresso para tratamento e análise das informações.

Tratamento das informações

As respostas oriundas dos questionários foram agrupadas por orientação terapêutica e sexo dos respondentes e categorizadas nos seguintes conjuntos: conversando com os pacientes sobre política, identificando temas políticos na situação terapêutica, identificando diferenças no material político em diferentes ambientes de trabalho, relacionando material político com a idade do paciente, relacionando material político com o sexo do paciente, lidando com temas políticos na situação terapêutica, mudando a maneira de lidar com material político, recebendo formação política, recebendo influências sobre atitudes políticas, atuando politicamente como cidadão, relacionando desenvolvimento psicológico e desenvolvimento político da personalidade.

As informações oriundas do grupo focal foram analisadas nas categorias identificando 
temas políticos na situação terapêutica, lidando com temas políticos na situação terapêutica e relacionando desenvolvimento psicológico e desenvolvimento político da personalidade. Em seguida, essas informações foram confrontadas com as dos questionários, com o intuito de aprofundar a investigação qualitativa-exploratória das respectivas questões.

O trabalho sobre cada uma das categorias foi estruturado da seguinte maneira: a) consolidado das falas dos participantes do "grupo questionário"; b) resumo das falas dos participantes do grupo focal; c) análise comparativa dos dois conjuntos de informações e d) discussão e conclusões.

\section{Discussão, conclusões e novos questionamentos}

Categoria 1 - Conversando com os pacientes sobre política

Todos os terapeutas conversam sobre temas políticos com seus pacientes, embora nenhum admita iniciar a conversa, talvez porque seja um cânone terapêutico aguardar que o paciente assuma a iniciativa pelo tema a ser introduzido na sessão. Conversar ou discutir temas políticos parece sugerir confronto de opiniões e eventuais desacordos, o que seria um elemento perturbador na aliança terapêutica. Restrições a conversar sobre política na situação terapêutica têm expressão em outras culturas: os resultados encontrados por Samuels (1995) mostram que $56 \%$ dos terapeutas de sua pesquisa internacional responderam afirmativamente, para $44 \%$ que informaram não discutir questões políticas. A principal alegação dos respondentes, segundo Samuels, foi a de que discutir política não era trabalho do terapeuta.

Categoria 2 - Identificando temas políticos na situação terapêutica

Os temas que surgem com mais freqüência na situação terapêutica, segundo os psicólogos que responderam ao questionário, são: questões econômicas, segurança e violência na sociedade, relações de poder no trabalho, diferenças ou conflitos de gênero, política nacional e preocupações ambientais. O grupo focal confirmou, no geral, as informações oriundas dos questionários, desdobrando-as em diversas outras questões. A dimensão trabalho (correspondente, no questionário, às questões econômicas e às relações de poder no trabalho) foi bastante enfatizada (desemprego, precarização, desqualificação social de certas atividades, falta de sentido, terceirização, falta de recursos para capacitação e aprimoramento profissional, sofrimento oriundo das relações de trabalho, assédio moral, sobrecarga de trabalho).

Os terapeutas mencionaram, ainda, a emergência dos preconceitos usuais, tais como o racial e o de gênero, e alguns menos visíveis, tais como o preconceito associado à origem regional e à velhice da mulher. Outro conjunto de informações referiu-se aos problemas de falta de urbanização, falta de moradia, fome, falta de recursos financeiros, falta de educação, injustiça, crise de papéis associada a gênero, crise de estrutura familiar, novos modos de sociabilidade entre jovens, individualismo e falta de projeto de vida na cidade. 
Essa profusão de aspectos mencionados faz contraste com certa reticência de alguns terapeutas em relação à sua percepção das queixas dos pacientes. Uma terapeuta de orientação psicanalítica, por exemplo, diz: "Meus pacientes até agora nunca trouxeram uma queixa da cidade. Eles estão realmente mergulhados dentro de um drama pessoal". A terapeuta fez uma distinção entre "drama pessoal" e questões da cidade. É como se fosse esperado que as questões da cidade aparecessem por si mesmas, desvinculadas da vida pessoal: aí, sim, seria mais fácil identificar os sofrimentos da cidade, pois é certo que o "drama pessoal" repousa sobre questões de caráter coletivo, relacionadas à forma de viver das pessoas na cidade. Parece que, aqui, estamos em face da dificuldade de "traduzir" as questões individuais em questões públicas, compartilhadas por um coletivo de pessoas, como diz Baumann (2000), ou então as traduzimos de maneira muito precária.

A expressão "drama pessoal" evoca a atuação da pessoa em um cenário que parece ter pouco a ver com o drama em si. Podemos questionar se a modalidade de atendimento terapêutico tem a ver com essa "insensibilidade" ao "pano de fundo" das questões sociopolíticas. Como transformar esse "pano de fundo", a "paisagem", em tema do trabalho psicológico, incorporando-o ao "drama"? Será que o atendimento individual de alguma forma autoriza o paciente a ser "individualista", como especula um dos terapeutas ao longo da discussão? A modalidade de atendimento grupal, em suas diversas formas, facilitaria a emergência e o tratamento da dimensão sociopolítica das queixas de nossos pacientes? O aprofundamento do trabalho terapêutico conduzirá necessariamente a maior abertura para as questões coletivas, não implicadas diretamente na queixa do paciente?

Categoria 3 - Identificando diferenças no material político em diferentes ambientes de trabalho

Observou-se tendência à resposta de que não existem diferenças substanciais no material que emerge nos contextos de consultório particular e institucional. Explicações oferecidas pelos terapeutas: nos diferentes ambientes, os temas aparecem sempre ligados à própria vida do paciente; muda a forma, porém, não o conteúdo; isso, segundo uma das terapeutas psicodramatistas, se deve ao fato de que as questões têm caráter intrapsíquico. Poderíamos dizer, também, que o "pano de fundo" sociopolítico tem muito de comum para todos os pacientes enquanto cidadãos, variando, evidentemente, a ênfase em uma ou outra questão ("forma", e não "conteúdo", como disse uma das terapeutas). O trabalho em grupo institucional, nas palavras do terapeuta reichiano, apareceu como propiciador da emergência de problemas comuns, portanto, coletivos, e daí, então, o caráter sociopolítico dos temas que emergem nesse contexto. É caso de se perguntar se o setting grupal não seria um facilitador para a configuração mais explícita de questões de caráter sociopolítico.

Categoria 4 - Relacionando o material político com a idade do paciente

De maneira geral, os terapeutas identificaram relação entre temas políticos apresentados na situação terapêutica e o momento de vida dos pacientes, e manifestaram alguma 
concordância quanto às especificidades de cada faixa etária, exceção feita às psicólogas de orientação psicanalítica, que negaram uma clara relação entre temática e idade.

Boa parte dos depoimentos parece indicar que pacientes na faixa dos 45-50-60 anos apresentam questões diretamente ligadas à vida da cidade, talvez com um certo sentido de "responsabilidade pelo mundo que deixarão para seus filhos e netos", como diz uma das terapeutas. Talvez o amadurecimento vital tenha algo do processo de individuação que conduza a pessoa às questões mais abrangentes da pólis. Em civilizações tradicionais, os mais velhos foram considerados referência dos valores sociais e éticos da comunidade, portadores de uma sabedoria vital que os qualificava para orientar e esclarecer os mais jovens e opinar sobre os destinos da comunidade. De toda forma, não parece ser esse o caso de nossa sociedade. Talvez na situação terapêutica dos nossos pacientes mais velhos esteja emergindo algo desse papel sociopolítico perdido.

Quanto à negativa das psicólogas psicanalíticas, caberia perguntar se isso resulta de características da própria abordagem analítica. Em sua pesquisa, Samuels (1995), ao constatar que os psicanalistas britânicos haviam dado o maior número de respostas "sem diferença", concluiu que isso reflete a lógica de uma abordagem clínica que lida com material político no nível intrapsíquico, simbólico ou transferencial, o que é corroborado pelas informações analisadas na categoria lidando com temas políticos na situação terapêutica. Nessa perspectiva, as diferenças de sexo e idade passam a ser consideradas menos significativas.
Categoria 5 - Relacionando o material político com o sexo do paciente

A maioria dos depoimentos negou a existência de diferenças entre homens e mulheres no que diz respeito ao material político apresentado na sessão. Comparativamente, parece que a idade é um fator que afeta o surgimento de material político mais do que o sexo. A questão merece estudos mais aprofundados, uma vez que as questões de gênero são tema corrente em nossa sociedade, e seria esperado que tanto sexo quanto idade fizessem diferença. Por outro lado, as vicissitudes das questões profissionais e econômicas que dizem respeito à inserção dos jovens no mercado de trabalho, bem como uma possível segregação social do idoso decorrente dos preconceitos em relação ao envelhecimento, estão diretamente ligadas à faixa etária.

Categoria 6 - Lidando com temas políticos na situação terapêutica

No trabalho realizado por Samuels, o autor definiu categorias para os modos de lidar com o material político que surge na situação terapêutica, a saber: nível simbólico/ intrapsíquico, no qual o terapeuta interpreta o material relacionando-o à dinâmica intrapsíquica do paciente; nível do significado, no qual o terapeuta busca o significado do tema para o paciente, relacionando-o com qualquer aspecto de sua vida, e um terceiro nível, que Samuels denominou realidade, no qual o terapeuta discute a questão tal como apresentada pelo paciente; o autor refere-se ainda a um quarto nível, que é o do envolvimento do terapeuta com o tema. Procurou-se identificar a presença dessas 
categorias de respostas em ambos os grupos pesquisados (questionário e grupo focal).

Nos questionários, $55 \%$ das respostas (11 de 20) referem-se à categoria simbólico, $45 \%$ (9 de 20) à categoria significado_ e $40 \%$ das respostas (8 de 20) fazem referência à categoria realidade. Observou-se uma ligeira tendência à interpretação do tema do ponto de vista intrapsíquico, simbólico ou transferencial (10 a 15\% superior às duas outras categorias). As respostas foram dadas por psicólogas e psicólogos analíticos, psicólogas de orientação psicanalítica e uma psicodramatista. Pode-se atribuir esse resultado ao viés da orientação teóricoclínica desses profissionais, de caráter analítico, interpretativo e simbólico. Contudo, $54 \%$ das respostas (6 de 11) da categoria simbólico aparecem associadas à categoria realidade (simbólico mais realidade). $\mathrm{Na}$ amostra internacional com a qual Samuels trabalhou, a percentagem global foi de $71 \%$ de respostas na categoria realidade, em suas várias combinações com as outras categorias, resultado que Samuels considerou expressivo e indicativo de que "esta é uma profissão mais 'política' do que se pensava" (Samuels, 1995, p. 266). A "amostra" do presente estudo não pode ser comparada à de Samuels, mas oferece um resultado (54\%) sobre o qual há que se pensar.

A categoria significado, que representa $45 \%$ das respostas, é representada por psicólogas psicodramatistas, psicoterapeuta breve, psicóloga gestaltista, psicóloga analítica, psicólogo reichiano e psicólogo de orientação múltipla. Apenas 22\% das respostas (2 de 9) aparecem combinadas com a categoria realidade. Comparativamente, significado mais realidade aparece menos do que simbólico mais realidade, respectivamente $22 \%$ e 54\%. Talvez isso se deva à "necessidade" de os profissionais "simbólicos" equilibrarem uma prática excessivamente interpretativa com certa atenção aos aspectos concretos da vida do paciente, enquanto aqueles que tratam o tema em termos de relevância ou significado pessoal para o paciente sintam menos essa necessidade.

A única resposta na categoria envolvimento profissional mais significado veio de uma das psicólogas analíticas: "As questões também me tocam, vivo na mesma cidade em que as pessoas que me procuram vivem, sendo assim, identifico-me com as dificuldades". Isso parece revelar o cuidado e o receio dos terapeutas de se exporem excessivamente em suas interações com os pacientes. De maneira geral, os terapeutas participantes do grupo focal manifestaram cautela para evitar que a sessão terapêutica se transforme em palco para uma infindável e polêmica discussão sobre questões políticas que possa não resultar em valor terapêutico.

Questões suscitadas por essa categoria exigirão estudo mais aprofundado. Orientações teórico-clínicas distintas, por exemplo, oferecem abertura diferenciada para o tratamento de temas políticos, como esta investigação sugere? E, nesse caso, abordagens grupais facilitariam a emergência de temas sociopolíticos e o respectivo tratamento? Em contrapartida, como se dá o processo de "aprendizagem" do paciente - supondo-se que esse processo de fato ocorra - sobre o que é "permitido" ou não na situação terapêutica e como se estruturam suas expectativas em relação ao tratamento que será dado ao tema? 
No que diz respeito à eficácia terapêutica, será necessário analisar mais profundamente o impacto - positivo e negativo - da exposição de pontos de vista do(a) terapeuta sobre os temas de caráter sociopolítico apresentados pelo paciente. Vimos que a relutância do(a) terapeuta quanto à manifestação de seu ponto de vista se funda, pelo menos em parte, no temor de perder o controle da situação terapêutica. E, nessa perspectiva, como dar atenção e consideração aos temas políticos que emergem na situação terapêutica sem perder de vista o locus específico do trabalho psicológico e sem que terapeuta e paciente se percam no emaranhado das opiniões e controvérsias sobre o tema? $\mathrm{E}$, ainda, o amadurecimento emocional do paciente conduzirá a um estágio em que ele passe a olhar a vida além de uma perspectiva apenas pessoal, ou seja, mais sociopolítica? Em sentido inverso, a elaboração de experiências sociopolíticas conduzirá a um incremento do desenvolvimento psicológico? Essas questões, embora não tenham sido respondidas de maneira conclusiva por este estudo, evocaram reflexões críticas e inquietantes dos participantes, justificando outras investigações.

Categoria 7 - Mudando a maneira de lidar com o material político

Observou-se, nos depoimentos, a tendência a valorizar a experiência profissional como algo que levaria o terapeuta a lidar melhor com a temática política que o paciente traz. Dentre todos, as psicanalistas e a terapeuta guestáltica são as que menos reportaram mudanças na forma de lidar com o material político na situação terapêutica, e as psicodramatistas as que mais contundentemente afirmaram ter experimentado mudanças. Aqui talvez estejamos diante de algumas determinações originárias da orientação teórico-clínica das abordagens.

Categoria 8 - Recebendo formação política

Pôde-se perceber ligeira tendência à resposta positiva no que se refere à discussão de temas políticos, nos diversos níveis de formação. Na especialização terapêutica, 6 dos 24 terapeutas (25\%) declararam ter tido formação sobre temas políticos (quatro terapeutas analíticos, um reichiano e um guestaltista). É de se especular se a orientação teórico-clínica não teria alguma influência no valor atribuído e na atenção dada ao tema.

Convém ressaltar que os resultados encontrados por Samuels indicam que apenas $23 \%$ dos terapeutas de sua amostra internacional afirmaram que os temas políticos entravam no processo de formação terapêutica. Samuels desconsiderou, para efeito comparativo, as respostas de russos e brasileiros, os primeiros pela altíssima taxa de retorno dos questionários (100\%), e os segundos pela menor taxa de retorno de todos os grupos (13\%). Lembremos, ainda, que a amostra brasileira, constituída por psicólogos analíticos, resultou em apenas sete respondentes (Samuels, 1995, p. 240). A taxa de resposta afirmativa dos brasileiros, apurada por Samuels - 58\% - refere-se tão somente a quatro terapeutas (p. 278). Considerando-se rigorosamente as respostas dos 11 terapeutas analíticos que responderam ao questionário deste estudo, $5(45,4 \%)$ indicaram que a temática política entrou no escopo da formação terapêutica, percentual inferior, portanto, ao encontrado por Samuels. Se 
considerarmos todos os terapeutas, 16 fazem referência a algum tipo de formação, não apenas na especialização de terapeutas, o que resulta em um percentual de $66,7 \%$. É claro que essa comparação é precária, dado o pequeno número de respondentes em ambos os grupos, o deste estudo e o de Samuels.

Os resultados sugerem que a temática política é discutida mais freqüentemente nos vários estágios da formação dos profissionais que antecedem a formação terapêutica especializada. De toda a sorte, fica o desafio de se apurar mais criteriosamente a participação da temática política nos programas de formação terapêutica das diversas abordagens teórico-clínicas.

Categoria 9 - Recebendo influências nas atitudes políticas

A diversidade de influências declaradas pelos terapeutas é grande. Não parecem ter sido destacadas diferenças entre as diversas orientações clínicas. Influências oriundas dos valores familiares, morais e religiosos são perfeitamente visíveis, como seria de se esperar, dada a formação cristã usualmente recebida por pessoas da faixa etária dos participantes, associada ao processo educacional.

As influências recebidas cobrem ampla gama de fatores, e, como era de se esperar, a partir dos estudos de socialização política (Bobbio, Mattecucci, \& Pasquino, 1991; Himmelweit, 1984), por influências parentais, formação religiosa, experiências decorrentes da origem étnica e racial, até experiências adultas da atividade profissional e de envolvimento mais direto com movimentos políticos, como, por exemplo, atividade sindical, política estudantil e participação em comícios políticos.

Um dos terapeutas analíticos e uma das terapeutas breves fazem menção explícita aos acontecimentos do período de ditadura militar vivida pelo País. Dada a faixa etária dos participantes (parte deles eram adolescentes e jovens adultos, então), esperávamos um aparecimento mais expressivo dessa questão. Nota-se a ausência, quase que completa, de referências a influências originadas de processos de formação graduada, tais como, por exemplo, curso superior e especialização, o que ratifica as informações levantadas e analisadas na Categoria 8 - Recebendo formação política. Essas constatações sinalizam a importância das fontes de socialização secundária para a formação das atitudes políticas dos terapeutas.

Categoria 10 - Atuando politicamente como cidadão

Identificou-se ligeira tendência para um ativismo político mais intenso no passado, quando os e as terapeutas eram mais jovens, provavelmente coincidindo com uma fase da vida de maior envolvimento e de contestação política mais intensa $(75 \%$ dos respondentes - 18 dos 24 - informaram atuação política no passado, enquanto $54 \%$ - 13 dos 24 informaram atuação política no presente). Com o passar do tempo, a tendência parece ser a de manter uma atividade política menos ostensiva, baixo envolvimento com associações e organizações e, no limite, reduzida ao voto. As análises de Samuels indicam algo semelhante (cerca de $67 \%$ dos respondentes se declararam ativos no passado e somente $33 \%$ ativos no presente), considerando-se as 
dificuldades de comparação entre as duas "amostras". No presente estudo, não houve referências explícitas a uma atividade política representada pela atuação terapêutica do profissional.

Categoria 11 - Relacionando desenvolvimento psicológico e desenvolvimento político da personalidade

Para os participantes do "grupo questionário", desenvolvimento político da personalidade tem a ver com: ser mais cidadão, agir de maneira diferente, ter consciência do micro e do macro (individual e coletivo), ter visão social, ser capaz de leituras diferenciados do contexto social, assumir posturas politicamente corretas, preocupar-se com o que vai além do indivíduo, perceber o ambiente e sua relação com ele, aproximação e distanciamento do mundo, assumindo uma presença diferenciada (visão crítica da realidade sociopolítica).

Os terapeutas consultados por questionário, de maneira geral, identificaram relação entre desenvolvimento político e desenvolvimento psicológico da personalidade. Os psicólogos analíticos (homens e mulheres) consideraram que a transformação pessoal, a maturidade pessoal, leva à mudança na atitude diante do coletivo. O nexo foi explicado evocandose a idéia de que a transformação pessoal (ampliação do campo de consciência, "apuração da alma", nas palavras de uma delas) leva à transformação social (ser mais cidadão, "agir de maneira diferente").

Para os participantes do grupo focal, o desenvolvimento político assume um caráter de engajamento em ações de voluntariado, envolvimento crítico com as questões coletivas, adoção de atitudes mais centradas no interesse coletivo, dentro de qualquer contexto (família, trabalho, comunidade). Implica, ainda, relação ética entre o eu e o outro, a condição de sujeito, protagonista da História.

Observou-se a manifestação unânime de que o desenvolvimento psicológico favorece o desenvolvimento político da personalidade. A superação das dificuldades emocionais pessoais, bem como o processo de diferenciação entre o eu e o outro, o coletivo social, possibilitaria ao indivíduo voltar-se para as questões coletivas. A sociedade torna-se melhor na medida em que os indivíduos resolvem adequadamente suas dificuldades emocionais. Segundo essa perspectiva, a relação entre desenvolvimento psicológico e desenvolvimento político é algo que podemos considerar desejável, mas não obrigatório, como resultado do processo psicoterápico. Acompanhemos o argumento: o cliente chega envolvido com seus problemas pessoais, o foco é em si mesmo. Somente à medida que os resolve, vê-se livre para pensar no coletivo, mas isso não é uma regra, não é um resultado necessário do processo de terapia ou do desenvolvimento psicológico. Parece estar mais ligado às convicções e aos ideais do terapeuta. A valoração cultural afeta os ideais terapêuticos, enfatizando mais os aspectos individuais ou os aspectos coletivos. O desenvolvimento emocional está imbricado com o contexto político-cultural da sociedade, com a forma de relacionar-se com o outro. O desenvolvimento político da personalidade se situaria como relação ética entre o eu e o outro. 
Em outra linha de pensamento, surgiu a idéia de que ambos os desenvolvimentos podem se dar simultaneamente, com a formulação de um conceito de saúde psicológica e política: como integração construtiva das diferenças, internas e externas (no plano individual da personalidade e no plano das relações políticas), dando atenção aos aspectos contraditórios e à sua integração. Isso resultaria em saúde individual, e, no plano político, o processo seria semelhante. A luta política teria como foco o bem-estar coletivo, e não a vitória de um determinado grupo sobre outro. Aqui parece ocorrer uma idealização de desenvolvimento político em que, à semelhança do desenvolvimento psicológico, talvez também idealizado, as diferenças possam se resolver em prol do bem-estar coletivo, e não nas afirmações de poder de grupos adversários. E onde ficariam, então, os inevitáveis confrontos e conflitos de projetos políticos distintos?

Alschuler (2002) chama a atenção para o fato de que os desenvolvimentos psicológico e político não se confundem, embora possam estabelecer entre si complexas relações. A consciência do poder transformador da ação individual, potencializada, eventualmente, pela articulação de ações coletivas, confere um caráter revolucionário à consciência individual, semelhante àquela produzida pelo desenvolvimento psicológico espontâneo ou induzido terapeuticamente. A retirada das projeções e a conseqüente integração da "sombra" - "os aspectos ocultos ou inconscientes de si mesmo, bons ou maus, que o ego ou reprimiu ou jamais reconheceu" (Sharp, 1993) - devem conferir maior objetividade à percepção e à análise das situações, favorecendo, em tese, a ação política. Isso é, mais ou menos, o que vimos nas respostas de nossos terapeutas, porém, o inverso não parece tão evidente. O esforço de compreensão política, a percepção e a vivência do destino comum, da "comunidade de destino", nas palavras de Safra (2004), com engajamentos concretos fundamentados na solidariedade dos que desejam transformar certa realidade, pode resultar em influxos ao desenvolvimento psicológico, à individuação, à criação de novos valores para a sociedade, conforme Jung (1916/2000) gostava de dizer. Não seriam essas as características de um desenvolvimento político da personalidade "suficientemente bom"? (Samuels, 1995).

\section{Ampliando a discussão}

No consultório se faz política o tempo todo! (Terapeuta psicodramatista, participante do grupo focal)

É necessário aprofundar o conceito de "desenvolvimento político da personalidade". Os estudos de socialização política, elaborados em países de tradição democrática, focalizam principalmente o processo pelo qual os novos integrantes da sociedade (crianças e jovens) se inserem na dinâmica das instituições políticas e no jogo de forças políticas dessa sociedade. Cada sociedade, democrática ou não, normatiza o que entende por "bom cidadão" ou "bom súdito". Princípios que podem ser adotados para caracterizar o que vem a ser um "bom" desenvolvimento político da personalidade, tais como os discutidos por Alschuler (2002) e Freire (1980), podem ser acusados de etnocentrismo e, sem demérito, certamente o são! Refletem uma concepção etnopsicológica de ser humano, em uma perspectiva específica de sociedades democráticas. 
Dependendo da definição que se adote para "desenvolvimento político da personalidade", a questão "o que decorre do quê?" pode ter uma resposta diferente. Em uma visão de ser humano socio-histórico, tenderíamos a pensar em processos correlatos, concomitantes, embora não redutíveis um ao outro, como diz Alschuler (2002). Provavelmente, o papel da educação e da aprendizagem (em diferentes níveis de socialização) será enfatizado. Numa visão mais centrada no intrapsíquico, duas perspectivas se delineiam: uma em que o desenvolvimento psicológico conduz "naturalmente" ao desenvolvimento político, e outra na qual, na melhor das hipóteses, o desenvolvimento político será facilitado pelo desenvolvimento psicológico, não ocorrendo necessariamente.

O fato de que "engajamentos" políticos possam ser "sintomas" de mau-funcionamento psíquico, como de fato a clínica muitas vezes demonstra, não deve ofuscar o potencial de desenvolvimento psíquico representado por essas experiências. Os "engajamentos" retiram a pessoa de seu isolamento, desmitificando atitudes solitárias de suposto apoio à cidadania e aos valores democráticos. A questão "engajamentos neuróticos" x "engajamentos saudáveis", por outro lado, pode vir a ser interessante vetor de pesquisa.

O treinamento profissional nos ensina a ter cuidado com o ordenamento da situação terapêutica. Elaboramos contratos de trabalho psicológico que regulam o relacionamento profissional e, ao mesmo tempo, oferecem um espaço continente e confiável para nossos clientes ou pacientes. Aprendemos a considerar todos os assuntos que são trazidos para a sessão. Mas, como os consideramos? A maioria de nós - os de formação analítica certamente - aprenderam a interpretar, do ponto de vista simbólico/intrapsíquico/ transferencial, os diferentes temas. Aliás, os temas se transformam em "temas analíticos", possuidores de um significado que a exegese analítica cuidará de explicitar. Evitamos "jogar conversa fora", "esquentar o assunto", como disse um dos colegas terapeutas, a fim de não nos afastarmos do núcleo da problemática psíquica de nossos pacientes.

Neste estudo, exploramos a possibilidade de que o material político trazido para a sessão - de fato, "político", comporta diferentes entendimentos por parte dos terapeutas - não deva necessariamente ser tratado sempre do ponto de vista simbólico/interpretativo. Às vezes, trata-se do mundo querendo entrar na vida do paciente, ou o paciente querendo sair para o mundo. Às vezes, é necessário ouvir o que o mundo tem a dizer ao paciente e o que este tem a dizer para o mundo... Cabe interpretar psicologicamente, mas cabe, igualmente, ouvir os reclamos do mundo e dialogar com ele.

Conversar ou discutir temas políticos na situação terapêutica se parece, às vezes, com "jogar conversa fora". Sugere, outras vezes, confronto de opiniões e ameaça de eventuais desacordos entre o profissional e o paciente, o que seria um elemento perturbador na aliança terapêutica. Compreende-se, então, que os terapeutas considerem que a escolha de temas políticos -principalmente daqueles mais ostensivos - é algo de natureza iminentemente pessoal e indiscutível, mesmo que a discussão se dê num contexto terapêutico. Os terapeutas, de maneira geral, 
valorizam o amadurecimento profissional como um fator que favorece o manejo da temática política, embora não haja unanimidade em relação a isso.

Vimos que a formação terapêutica especializada, de maneira geral, não dá atenção diferenciada para o manejo de material político. Nessa questão, parece haver também diferenças entre as abordagens terapêuticas. As visões apresentadas pelos terapeutas sobre desenvolvimento psicológico e político da personalidade são duas, ambas centradas no intrapsíquico: uma em que o desenvolvimento psicológico conduz "naturalmente" ao desenvolvimento político e outra na qual o desenvolvimento político é favorecido pelo desenvolvimento psicológico, mas não ocorre necessariamente. Engajamentos políticos são vistos, por alguns, como "sintomas" de mau-funcionamento psíquico, perdendo-se de vista o potencial de desenvolvimento psíquico representado por essas experiências.

A observação de Samuels (1995, p. 300) de que há uma cisão entre a face pública da profissão, que se apresenta apolítica, e a face privada, representada por profissionais que têm uma história política, que vivem engajamentos, que às vezes são céticos em relação à "coisa política", outras vezes esperançosos, parece ser corroborada por este estudo. Vários de nossos terapeutas, à semelhança daqueles consultados por Samuels, procuram um equilíbrio entre a consideração do "mundo interior" e a do "mundo exterior" de seus pacientes. Esses profissionais terão, inevitavelmente, que rever os pressupostos de suas abordagens clínicas, de maneira a encontrar uma equação que contemple satisfatoriamente essa realidade.

A política dos movimentos psicoterapêuticos, com seus profissionais e suas organizações, se coloca como "pano de fundo" da experiência terapêutica, tal como muitos dos terapeutas participantes desta pesquisa se referem à dimensão política da vida de seus pacientes como um "pano de fundo" de suas questões pessoais. Talvez, em ambos os casos, o "fundo" faça parte, efetivamente, da "figura". A "tirania" do método remete a um aspecto da política dos movimentos psicoterapêuticos que se refere ao grau de tolerância entre as diversas abordagens psicológicas. Também aqui a Psicologia e suas aplicações podem se beneficiar de uma abordagem política para lidar com suas incompreensões, suas intolerâncias e suas dificuldades de diálogo.

\section{Considerações finais}

A política atravessa a condição humana. Se o mundo é construído pelo nosso interesse comum em relação a ele, é aqui que se dá o embate dos interesses, das convergências e das divergências. O mundo que construímos nos adoece, ao tempo em que adoece conosco. Os jornais do dia nos lembram que o mundo se apresenta cruel, injusto, feio, moral e esteticamente. Nosso paciente lê os mesmos jornais, assiste os noticiários televisivos e sente na carne esse lado da verdade assim que sai de casa...

Acreditamos que nosso trabalho, como terapeutas, é cuidar da pessoa que ali se apresenta, com suas dores e sofrimentos. Esperamos fazer o melhor possível para que ela supere as tiranias do próprio caráter. A 
pesquisa realizada no âmbito deste estudo demonstra, no limitado espectro de sua validade, que nosso paciente vive imerso no próprio "drama" pessoal em um mundo que serve de palco e cenário para sua atuação sofredora. Se o mundo também sofre, ele, paciente, não se dá conta disso. Mas, e nós, terapeutas? Damos atenção suficiente ao fato? Não sabemos muito bem o que fazer! Conversamos com nossos pacientes sobre questões da cidade, se eles as trouxerem para a situação terapêutica. Não iniciamos conversas sobre tais temas porque acreditamos que essa iniciativa seria imprópria: cabe ao paciente expor sua questão. Temos razões teóricas e clínicas para assim proceder. Nossos terapeutas foram claros sobre isso. Privamo-nos, então, de propor outras questões relacionadas com os assuntos da pólis.

De toda sorte, acreditamos que o amadurecimento emocional do paciente, apoiado por análise ou psicoterapia, deverá conduzi-lo a um estágio em que seja capaz de olhar por cima do muro, para além de seu próprio quintal. O exercício de uma cidadania democrática advirá, na melhor das hipóteses, com o tempo. Advirá? Todos admitimos que as dificuldades que conduzem pacientes ao nosso consultório (na verdade, a qualquer locus de atendimento) se originam de suas experiências de vida de alguma forma negativas ao seu desenvolvimento psicológico. Se o problema estiver no mundo, ainda assim, algo precisa ser retificado na atitude e na capacidade do paciente para lidar com esse "mundo doente".

Todos concordamos que é necessário compreender nosso paciente no contexto de sua vida, de toda a sua vida. Alguns de nós, contudo, pensamos que alguns aspectos devam ser observados com maior atenção. Cada um de nós, em suas convicções, acaba por dar maior atenção a algumas "paisagens da alma" do que a outras. Isso é mais ou menos inevitável. Processo similar ocorre com os pacientes. Atenção seletiva é o nome. No final, olhamos para o horizonte que terapeuta e paciente, com diferentes graus de participação, apontam. Trabalhamos com o que nosso paciente nos traz e, eventualmente, sempre que pensamos ser proveitoso do ponto de vista terapêutico, chamamos a atenção para algum aspecto desapercebido pelo paciente.

Assim, somos cautelosos com nossas intervenções. Desejamos evitar que a sessão se transforme em palco para uma polêmica da qual não queremos participar, pelo menos não ali, nem naquela hora. Seria bom, então, como disse um de nossos terapeutas, "procurar realmente um grupo de debate político para discutir política em termos políticos, sem nenhuma pretensão terapêutica". Porém, não estamos certos de que a discussão política não tenha efeitos terapêuticos! O que dizer do poder subjetivamente restaurador de experiências sociopolíticas de qualidade vividas pela pessoa, já que admitimos de maneira unânime o poder psicológico deletério de outras tantas experiências vitais?

Ao mencionar "experiências sociopolíticas de qualidade", destaco uma questão que emergiu na pesquisa de campo e que precisa ser aprofundada, seja no âmbito da educação, seja no da psicoterapia. Talvez fosse melhor dizer "experiência 
subjetivamente qualificadora", ou seja, um tipo de experiência na qual o sujeito assume o papel de autor da sua história política, da sua vida na Cidade. Talvez, como quer Guattari (2000), a psiquê se agarre em fixações arcaicas apenas enquanto nenhum engajamento a faz projetar-se para o futuro. No fundo, é isso que objetivamos com a análise ou psicoterapia: o paciente assumir o protagonismo, a condição de autor de sua existência, autoria paradoxal, dadas as multideterminações psíquicas e sociopolíticas, mas ainda assim, autoria.

Precisamos de referências que dêem conta da complexidade representada pelas três ecologias de que nos fala Guattari: as relações sociais, o meio ambiente e a subjetividade, a idéia de um mundo que não se resume em ser "palco" ou "cenário" das aventuras humanas, mas, ao contrário, interage com os protagonistas humanos, estabelecendo suas condições e exigindo seus direitos e inserindo uma nova perspectiva de saúde e bem-estar. O mundo não deixa de ser um local onde elaboramos nossa alma - o fazer a alma, como Hillman (1992) gosta de dizer - mas com o qual mantemos um intercâmbio de experiências telúricas, tecnológicas e humanas, algo que a mentalidade de povos ancestrais parece ter compreendido melhor do que nós.

O processo de individuação humana ganha uma dimensão na qual, ao mesmo tempo em que nos diferenciamos dos coletivos sociopolítico e arquetípico, como afirmam os psicólogos junguianos, reconhecemos nossa inextrincável relação com tudo o que existe, aumentando as exigências éticas em relação aos valores que criamos para as três ecologias. A terapia para um mundo doente não virá apenas dos profissionais psi. Todos aqueles que estão em posição de intervir nas instâncias subjetivas e coletivas, sejam os que atuam profissionalmente na política, na saúde, na educação, na cultura, sejam artistas, urbanistas, arquitetos, esportistas, enfim, cidadãos em geral, cada qual em seu limitado âmbito, todos se tornam terapeutas do mundo! Nós, profissionais psi, temos nossa tarefa de casa: reavaliar nossos referenciais, nossos métodos e práticas, de modo a integrarmos adequadamente em nosso trabalho a dimensão política do self. Essa tarefa passa, necessariamente, pela articulação com outros campos do saber e do fazer humanos. 


\section{Roque Tadeu Gui}

Mestre em Psicologia pela Universidade de Brasília (UnB)

Psicólogo Clínico/Universidade de Brasília (UnB)

\section{Endereço para envio de correspondência:}

SHIN QL 1, Conjunto 2, Casa 15 - Lago Norte, Brasília - DF - Brasil - CEP: 71505-025

E-mail: roque.tadeu@gmail.com

\section{Recebido 13/03/2008 Reformulado 22/01/2009 Aprovado 26/01/2009}

Alschuler, L. R. (2002). Jung e política. In P. Young-Eisendrath \& T. Dawson (Orgs.), Manual de Cambridge para estudos junguianos (pp. 262-272, D. Bueno, Trad.). Porto Alegre: Artmed. (Trabalho original publicado em 1997)

Arendt, H. (2002). O que é política? (3a ed., U. Ludz, Ed., R. Guarany, Trad.). Rio de Janeiro: Bertrand Brasil. (Trabalho original publicado em 1993)

Bauman, Z. (2000). Em busca da política (M. Penchel, Trad.). Rio de Janeiro: Zahar. (Trabalho original publicado em 1999)

Bobbio, N., Mattecucci N., \& Pasquino, G. (1991). Dicionário de política (3a ed., Vol. 2, C. V. Carmen et al., Trads.). Brasília, DF: Editora UnB; Linha Gráfica Editora. (Trabalho original publicado em 1983)

Bock, A. M. B. (1999). Aventuras do Barão de Münchhausen na psicologia. São Paulo: EDUC; Cortez.

Freire, P. (1980). Pedagogia do oprimido (8a ed.). Rio de Janeiro: Paz e Terra. (Trabalho original publicado em 1970)

Guattari, F. (2000). As três ecologias (10a ed., M. C. F. Bittencourt, Trad.). Campinas, SP: Papirus.

Gui, R. T. (2003). Grupo focal em pesquisa qualitativa aplicada: intesubjetividade e construção de sentido. Psicologia: Organizações e Trabalho, 3(1), 135-159.

Gui, R. T. (2005). Psiquê na pólis: individuação e desenvolvimento político da personalidade. Dissertação de Mestrado em Psicologia, Universidade de Brasília, Brasília, DF.
Hillman, J. (1992). Psicologia arquetípica (G. Barcellos \& L. Rosemberg, Trads. e Eds.). São Paulo: Cultrix. (Trabalho original publicado em 1983)

Hillman, J. (1993). Cidade \& alma (G. Barcellos \& L. Rosemberg, Trads. e Eds.). São Paulo: Studio Nobel.

Himmelweit, H. T. (1984). La socialización política. Revista Internacional de Ciencias Sociales. Dimensiones Políticas de la Psicología, (96), 257-278.

Jung, C. G. (2000). Adaptação, individuação e coletividade. In C. G. Jung, Obras completas de Carl Gustav Jung (Vol. 18-2, pp. 21-26, E. Orth, Trad.). Petrópolis, RJ: Vozes. (Trabalho original publicado em 1916)

Safra, G. (2004). A poética na clínica contemporânea. Aparecida, SP: Idéias e Letras.

Samuels, A. (1995). A psique política (R. Fiker \& M. E. Fiker, Trads.). Rio de Janeiro: Imago. (Trabalho original publicado em 1993)

Sharp, D. (1993). Léxico junguiano. Dicionário de termos e conceitos (R. Milanez, Trad.). São Paulo: Cultrix. (Trabalho original publicado em 1991)

Vasconcelos, E. M. (2002). Complexidade e pesquisa interdisciplinar. Epistemologia e metodologia operativa. Petrópolis, RJ: Vozes. 